IP $\rightleftharpoons$ B

\title{
Dispersão de sementes, regeneração e rebrota de Pinus taeda no Planalto Norte do Estado de Santa Catarina, Brasil
}

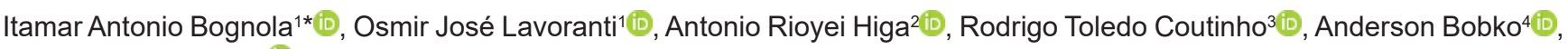 \\ Ulisses Ribas Junior ${ }^{5}$ (i) \\ ${ }^{1}$ Embrapa Florestas, Estrada da Ribeira, Km 111, CP 319, CEP 83411-000, Colombo, PR, Brasil \\ ${ }^{2}$ Universidade Federal do Paraná, Av. Pref. Lothário Meissner, 3400, Jardim Botânico, CEP 80210-170, Curitiba, PR, Brasil \\ ${ }^{3}$ Arauco do Brasil S.A., Rua Roberto Hauer, 160, Hauer, CEP 81610-180, Curitiba, PR, Brasil \\ ${ }^{4}$ Eldorado Brasil, Rod. Marechal Rondon, s/n, Km 641, CEP 16901-340, Andradina, SP, Brasil \\ ${ }^{5}$ Ribas Gestão de Agronegócios e Florestas Ltda., Rua do Seminário, 80, Centro, CEP 89295-000, Rio Negrinho, SC, Brasil
}

"Autor correspondente:

itamar.bognola@embrapa.br

Termos para indexação:

Ecologia vegetal

Espécies introduzidas

Sustentabilidade

Index terms:

Plant ecology

Introduced species

Sustainability

Histórico do artigo:

Received in 18/05/2018

Accepted in 23/11/2018

Published in 29/12/2018

doi: 10.4336/2018.pfb.38e201801651
Resumo - Os reflorestamentos de pinus abrangem cerca de 1,6 milhões de ha no Brasil. Suas espécies são tidas como exóticas invasoras, ou seja, apresentam potencial para modificar ambientes naturais. Procurou-se caracterizar os aspectos de dispersão, estabelecimento e controle de Pinus taeda L., a fim de avaliar o seu potencial como espécie invasora sob diferentes condições. Foi estudada a dispersão/viabilidade de sementes de P. taeda nas direções Norte, Sul, Leste e Oeste, distantes da bordadura de um povoamento comercial da espécie a $25 \mathrm{~m}, 50 \mathrm{~m}, 75 \mathrm{~m}, 100 \mathrm{~m}, 125 \mathrm{~m}$ e $150 \mathrm{~m}$. Foi avaliada a germinação em ambiente de floresta preservada e em ambientes com maior incidência de luz em 11 diferentes locais, sendo distribuídas 800 sementes a lanço. A rebrota foi avaliada em árvores cortadas a $10 \mathrm{~cm}$ do solo, tanto em locais bem drenados quanto em locais mais úmidos. A disseminação e germinação de sementes foram maiores na direção Sul e até $25 \mathrm{~m}$. Constatou-se que na floresta natural clímax, sem luz e no sub-bosque nenhuma semente germinou. Nos locais com maior luminosidade e umidade do solo mais uniforme durante todo o ano as sementes germinaram e se estabeleceram. Não foram observadas rebrotas nas árvores cortadas.

\section{Seeds dispersal, regeneration and regrowth of Pinus taeda in North Plateau of Santa Catarina State, Brazil}

\begin{abstract}
Pinus plantations cover approximately 1.6 million ha in Brazil. Since pines are considered to be alien invaders with the potential to modify natural environments, the aim of this study was to evaluate seed dispersal, establishment and control of Pinus taeda L., in order to characterize its biological invasion potential under different situations. We studied the dispersal/viability of pine seeds at $25 \mathrm{~m}, 50 \mathrm{~m}, 75 \mathrm{~m}, 100 \mathrm{~m}, 125 \mathrm{~m}$ and $150 \mathrm{~m}$ for from the border of a commercial stand, in North, South, East and West directions. Besides, 800 seeds of this species were sown in 11 different sites, ranging from a preserved natural forest to open habitats, in order to evaluate the regeneration potential. Regrowth was also monitored in stumps cut at $10 \mathrm{~cm}$ above ground, in well drained or moist sites. Seed dispersal and germination were higher in the South direction and up to $25 \mathrm{~m}$. In the preserved forest no seed germinated, probably due to low light incidence, while in more open habitats they not only germinated but also established. Regrowth was not observed under any studied condition.
\end{abstract}




\section{Introdução}

Dentre os principais gêneros florestais plantados no país, Eucalyptus e Pinus se destacam em termos de área cultivada e como importante fonte de matéria-prima para o setor industrial florestal brasileiro. Este setor é responsável por aproximadamente $1,1 \%$ do produto interno bruto (PIB) (Indústria Brasileira de Árvores, 2017), consequência de sua alta competitividade em nível internacional, sendo representado principalmente pelas indústrias de celulose e papel, de chapas de madeira e pela siderurgia à base de carvão vegetal.

Os reflorestamentos de Pinus abrangem cerca de 1,6 milhões de ha no Brasil, principalmente na Região Sul em áreas de grande diversidade de solos, clima, relevos e altitudes, mantendo-se a área praticamente inalterada nos últimos anos (Indústria Brasileira de Árvores, 2017).

Projeções mais recentes indicam que a população mundial deve atingir 9,1 bilhões de pessoas até 2050 . Para atender essa população e sua demanda crescente por commodities e bioenergia, em um cenário de baixo carbono, energias renováveis e desmatamento líquido zero, serão necessários 250 milhões de ha adicionais de florestas plantadas no mundo (Indústria Brasileira de Árvores, 2017).

Ainda, conforme a Indústria Brasileira de Árvores (2017), as florestas plantadas reduzem a pressão sobre as florestas naturais, contribuindo para a conservação da biodiversidade e muitos outros serviços, como a regulação do fluxo hídrico, da polinização, do controle do clima e formação de estoques de carbono.

Segundo Vasques et al. (2007), é importante compreender melhor a função das espécies de Pinus ao longo dos processos econômico, social e ambiental, uma vez que a condição atual de uso e aplicação desse gênero sustenta uma cadeia produtiva importante para a região Sul e para o país.

Por outro lado, as espécies de Pinus, são tidas como exóticas invasoras, entendendo-se com isso que apresentam potencial para alterar sistemas naturais. A produção de grandes quantidades de sementes pequenas e aladas, que são dispersas pelo vento a longas distâncias, e a maior longevidade das mesmas as incluem como de alto risco de invasão biológica (Richardson, 2006; Simberloff, 2009, Lockwood et al., 2009; Simberloff et al., 2010; Zenni \& Ziller, 2011; Zenni \& Simberloff, 2013; Instituto Hórus, 2016; Tomazello Filho et al., 2017).
O programa internacional sobre espécies invasoras da Nature Conservancy (Global Invasive Species Programme, 2001), cita o Pinus como um dos principais gêneros de plantas invasoras. As plantas exóticas invasoras, por terem grande capacidade de se estabelecerem, têm a tendência de aumentar suas populações com o passar do tempo, ampliando sua área de ocupação em locais que antes apresentavam outros usos, incluindo aqueles anteriormente ocupados por florestas naturais (Ziller, 2000; Lockwood et al., 2009; Simberloff et al., 2010).

Vários autores registram áreas de invasão biológica por P. taeda, tanto nos Campos Gerais, no Paraná, em Campos de Cima da Serra e em alguns locais nos Pampas do Rio Grande do Sul e em Santa Catarina, em algumas áreas de restinga, bem como no Cerrado em São Paulo (Ziller, 2001; Foelkel \& Foelkel, 2008; Falleiros et al., 2011; Bechara et al., 2013; Zenni \& Simberloff, 2013; Miashike, 2015; Ramos, 2015; Pivello, 2015).

O manejo de espécies exóticas invasoras é parte fundamental das estratégias de conservação da biodiversidade e requer uma abordagem multidisciplinar e integrada (Zenni \& Ziller, 2011; Instituto Hórus, 2016). A prevenção e a detecção precoce compreendem as técnicas de melhor custo-benefício que podem ser utilizadas para reduzir o impacto de espécies exóticas invasoras. O seu manejo efetivo requer uma abordagem coordenada que envolve todos os níveis de governo no estabelecimento de marcos legais e políticas públicas, incluindo esforços de educação e capacitação que possam atingir técnicos e estender-se ao setor privado e à sociedade civil.

A relevância deste estudo está, portanto, na tentativa de se obter indicadores do meio físico, a fim de estimar o potencial invasor desta espécie em ecossistemas naturais (degradados ou não), no sentido de contribuir para a convivência pacífica entre os interesses produtivos e da conservação da biodiversidade.

Nesse contexto, são objetivos deste trabalho caracterizar os aspectos de invasão biológica do P. taeda, considerando seu potencial de dispersão e germinação; do potencial de estabelecimento em diferentes ambientes do Planalto Norte Catarinense e do controle do P. taeda em ambientes externos aos plantios comerciais. 


\section{Material e métodos}

Os estudos foram desenvolvidos em plantios comerciais de Pinus taeda da empresa Battistella Florestal S.A., em fazendas localizadas nos municípios de Rio Negrinho (2615'18''S e 49 31'09' W) e Doutor Pedrinho (26 $42^{\prime}$ '57' $\mathrm{S}$ e 49 $29^{\circ}$ '09' $\mathrm{W}$ ), ambos situados no Planalto Norte do Estado de Santa Catarina.

O estudo contou com três fases distintas: a) disseminação/viabilidade das sementes de P. taeda; b) potencial de crescimento de $P$. taeda em áreas externas aos plantios comerciais; c) métodos de controle de $P$. taeda, em ambientes tidos como de invasão biológica.

\section{Avaliação do potencial de dispersão de sementes}

Avaliaram-se os efeitos das condições meteorológicas (direção e velocidade do vento, umidade relativa do ar, temperaturas e precipitações médias mensais e anuais), na distribuição espaço-temporal da dispersão de sementes de P. taeda. Foi utilizado para este experimento, como fonte de sementes, um talhão comercial de $P$. taeda com 30 anos de idade, localizado na fazenda Cerro Azul Gleba B.

Foi estudada a dispersão/viabilidade das sementes nos quatro quadrantes cardinais (norte, sul, leste e oeste), em seis diferentes distâncias a partir da bordadura do povoamento: $25 \mathrm{~m}, 50 \mathrm{~m}, 75 \mathrm{~m}, 100 \mathrm{~m}, 125 \mathrm{~m}$ e $150 \mathrm{~m}$.

As parcelas de estudo estabelecidas em cada um dos quadrantes cardinais apresentavam $25 \mathrm{~m} \times 8 \mathrm{~m}$, onde, para cada tratamento (entenda-se por tratamento as seis diferentes distâncias), foram instaladas caixas (1 m x $1 \mathrm{~m}$ ) receptoras de sementes (Figura 1), em posição de inclinação voltada para o talhão-fonte de sementes, com quatro repetições cada.

As caixas possuíam na parte inferior tela de nylon (malha 1,6 $\mathrm{mm}$ ), a qual permitia a passagem da água das chuvas e retinha as sementes de pínus. Na parte superior, as caixas foram cobertas com tela de arame galvanizado (malha 1,3 cm), de modo a permitir a entrada das sementes e impedir a ação predatória de pássaros ou outros pequenos animais às sementes ali depositadas.

As coletas de sementes de $P$. taeda se deram sempre no início de cada mês, nos períodos de abril a setembro de 2005 e maio a setembro de 2006, meses de início e final, respectivamente, da queda de sementes. Para a quantificação das distâncias de dispersões das sementes em relação ao talhão-fonte, foram feitas coletas e contagem das sementes, mensalmente, e testes de germinação, ao longo de dois anos consecutivos.
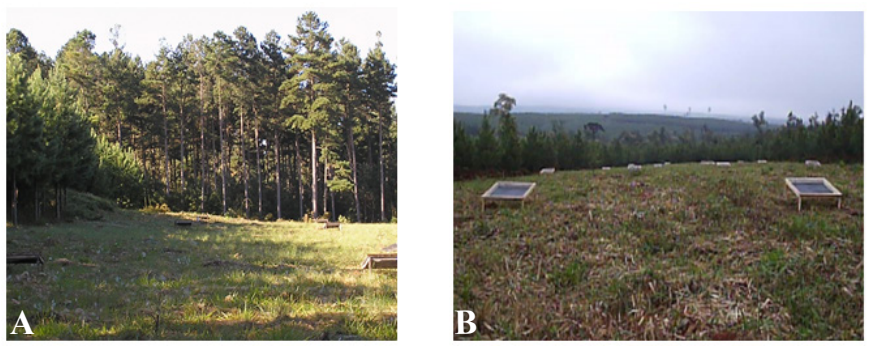

Figura 1. Plantio comercial de Pinus taeda com 30 anos de idade, onde foi instalado o estudo de dispersão/viabilidade de sementes, em orientação norte (A); e aspectos da distribuição das caixas receptoras (B) em seis diferentes distâncias na Fazenda Cerro Azul, Battistella Florestal S.A.

Figure 1. Commercial stand of Pinus taeda, 30 years old, for the study of seed dispersal/viability in north orientation (A); and aspects of the receptor boxes distribution (B) at six different distances at Fazenda Cerro Azul, Battistella Florestal S.A.

As sementes coletadas por parcela foram levadas ao Laboratório de Melhoramento Florestal (LAMEF) da Universidade Federal do Paraná (UFPR) para serem imediatamente pesadas e, posteriormente, submetidas a um tratamento pré-germinativo, com imersão em água a $5{ }^{\circ} \mathrm{C}$ em câmara fria por $48 \mathrm{~h}$. Após o pré-tratamento, as sementes foram colocadas para germinar, para a verificação da capacidade germinativa, considerando as várias distâncias e as diferentes épocas no ano.

Foi instalada uma estação meteorológica automática distante a $3 \mathrm{~km}$ dos experimentos, cujos equipamentos, para a obtenção dos dados meteorológicos, foram colocados em uma antena numa área livre distante $100 \mathrm{~m}$ de uma residência. Os dados eram registrados em um computador fixado dentro desta residência, funcionando $24 \mathrm{~h}$ por dia, a fim de melhor compreender a influência dos fatores climáticos, como a direção e velocidade dos ventos predominantes, a umidade relativa do ar, a temperatura média e a precipitação média, na dispersão das sementes de $P$. taeda, ao longo do período de dois anos de estudos. 


\section{Avaliação do potencial invasor de Pinus taeda em diferentes ambientes}

Foram instaladas quatro parcelas de $25 \mathrm{~m}^{2}(5 \mathrm{~m} \times 5 \mathrm{~m})$ em onze ambientes de estudos em áreas externas aos plantios comerciais de $P$. taeda, considerando variações em luminosidade e classes de solos (Tabela 1). Demarcou-se uma subparcela de $1 \mathrm{~m}^{2}$ (Figura 2A) dentro de cada ambiente proposto, onde foram distribuídas 800 sementes de $P$. taeda a lanço, em condições de pré-germinação (ou seja, já quebrada a sua dormência), a fim de se verificar a quantidade de sementes germinadas e seu desenvolvimento.

Estas subparcelas foram fechadas lateralmente com tela sombrite de $25 \%$ de proteção, presa lateralmente com madeira e coberta com tela de passarinho, para evitar danos por pequenos roedores ou pássaros (Figura 2B).

Todas as sementes utilizadas neste experimento foram obtidas do mesmo lote/procedência. Foi feito monitoramento mensal da emergência e crescimento das plântulas, durante 18 meses.
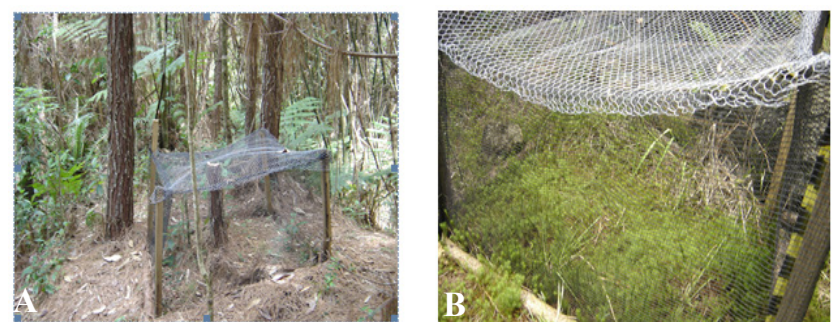

Figura 2. Estudo do local mais propenso à invasão por Pinus taeda: (A) detalhe da parcela de $1 \mathrm{~m}^{2}$ em capoeira; (B) detalhe da cobertura da parcela de $1 \mathrm{~m}^{2}$.

Figure 2. Study of the most prone site to invasion by Pinus taeda: (A) detail of the $1 \mathrm{~m}^{2}$ plot in early stage of forest regeneration (capoeira); (B) detail of the plot of $1 \mathrm{~m}^{2}$ coverage.
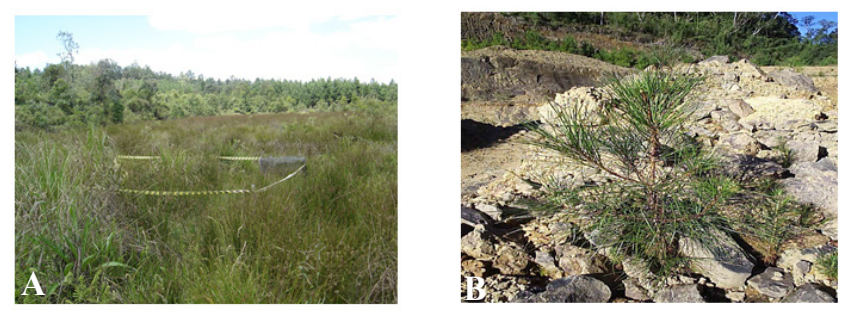

Figura 3. Crescimento de Pinus taeda em diferentes ambientes: (A) detalhe da parcela em banhado; (B) ambiente da parcela em pedreira abandonada.

Figure 3. Growth of Pinus taeda in different sites: (A) detail of the plot in a swamp site; (B) environment of plot in abandoned rock mining.
Tabela 1. Ambientes selecionados para avaliação da emergência e desenvolvimento das plântulas de Pinus taeda, considerando variação de luminosidade e classes de solos.

Table 1. Selected sites to evaluate emergency and growth of Pinus taeda seedlings, considering differences in light incidence and soils class.

\begin{tabular}{|c|c|c|c|}
\hline Local & Luminosidade & Solo & Figura \\
\hline Banhado & $\begin{array}{l}\text { alta } \\
\text { luminosidade }\end{array}$ & $\begin{array}{l}\text { solos profundos e } \\
\text { hidromórficos }\end{array}$ & $3 \mathrm{~A}$ \\
\hline $\begin{array}{l}\text { Pedreira } \\
\text { abandonada }\end{array}$ & $\begin{array}{l}\text { alta } \\
\text { luminosidade }\end{array}$ & $\begin{array}{l}\text { solos muito rasos } \\
(<25 \mathrm{~cm} \text { de espessura) } \\
\text { associados a } \\
\text { afloramentos rochosos }\end{array}$ & $3 \mathrm{~B}$ \\
\hline $\begin{array}{l}\text { Nascentes } \\
\text { d'água em área } \\
\text { de preservação } \\
\text { permanente }\end{array}$ & $\begin{array}{l}\text { moderada } \\
\text { luminosidade }\end{array}$ & $\begin{array}{l}\text { sem presença de solo } \\
\text { desenvolvido, são } \\
\text { caracterizadas como } \\
\text { "Tipos de Terrenos" }\end{array}$ & - \\
\hline $\begin{array}{l}\text { Unidade de } \\
\text { Conservação } \\
\text { em Floresta } \\
\text { Ombrófila } \\
\text { Mista, em } \\
\text { estágio de } \\
\text { regeneração } \\
\text { médio a } \\
\text { avançado, do } \\
\text { Instituto de } \\
\text { Meio Ambiente } \\
\text { de Santa } \\
\text { Catarina }\end{array}$ & $\begin{array}{l}\text { dossel fechado, } \\
\text { sem presença de } \\
\text { luminosidade }\end{array}$ & $\begin{array}{l}\text { solos moderadamente } \\
\text { profundos do tipo } \\
\text { Cambissolos }\end{array}$ & - \\
\hline Taquaral & $\begin{array}{l}\text { dossel fechado, } \\
\text { baixa entrada de } \\
\text { luminosidade }\end{array}$ & $\begin{array}{l}\text { solos moderadamente } \\
\text { profundos do tipo } \\
\text { Cambissolos }\end{array}$ & - \\
\hline $\begin{array}{l}\text { Lajeado com } \\
\text { gramíneas }\end{array}$ & $\begin{array}{l}\text { alta } \\
\text { luminosidade }\end{array}$ & $\begin{array}{l}\text { solos pouco profundos } \\
\text { do tipo Neossolos } \\
\text { Litólicos }\end{array}$ & - \\
\hline $\begin{array}{l}\text { Pastagem } \\
\text { natural }\end{array}$ & $\begin{array}{l}\text { alta } \\
\text { luminosidade }\end{array}$ & $\begin{array}{l}\text { solos profundos do tipo } \\
\text { Cambissolos }\end{array}$ & - \\
\hline $\begin{array}{l}\text { Pastagem } \\
\text { queimada }\end{array}$ & $\begin{array}{l}\text { alta } \\
\text { luminosidade }\end{array}$ & $\begin{array}{l}\text { solos profundos do tipo } \\
\text { Cambissolos }\end{array}$ & - \\
\hline $\begin{array}{l}\text { Capoeira } \\
\text { invadida }\end{array}$ & $\begin{array}{l}\text { luminosidade } \\
\text { moderada }\end{array}$ & $\begin{array}{l}\text { solos profundos do tipo } \\
\text { Cambissolos }\end{array}$ & - \\
\hline Capoeirinha & $\begin{array}{l}\text { luminosidade } \\
\text { moderada }\end{array}$ & $\begin{array}{l}\text { solos profundos do tipo } \\
\text { Cambissolos }\end{array}$ & - \\
\hline $\begin{array}{l}\text { Capoeira em } \\
\text { APP }\end{array}$ & $\begin{array}{l}\text { luminosidade } \\
\text { moderada }\end{array}$ & $\begin{array}{l}\text { solos profundos do tipo } \\
\text { Cambissolos }\end{array}$ & - \\
\hline
\end{tabular}

Utilizou-se luxímetro, em dias de céu sem nuvens, para a medição da taxa de intensidade da luz (Lux) incidente nestas parcelas ( $5 \mathrm{~m}$ x $5 \mathrm{~m}$ e $1 \mathrm{~m} \times 1 \mathrm{~m})$. Também, fez-se estudos de fotogrametria e fotointerpretação em fotos aéreas pancromáticas de 1982, período anterior ao plantio de pínus nas proximidades dos locais de estudo, a fim de se verificar possíveis clareiras que poderiam ter facilitado a invasão do pínus em alguns destes locais. Após o monitoramento de 18 meses, coletou-se de cada subparcela uma amostra de solo de $1 \mathrm{~m}$ x $1 \mathrm{~m}$ x 0,05 m, 
excluindo-se a serapilheira e os vegetais presentes. Esta amostra foi colocada em casa de vegetação, onde foi feito, por um período de 2 meses, a irrigação (mantendose a capacidade de campo) e a análise semanal da emergência de plântulas de pínus remanescentes.

\section{Avaliação do potencial de controle de Pinus taeda}

Foram instaladas quatroparcelas de $100 \mathrm{~m}^{2}(10 \mathrm{~m} \times 10 \mathrm{~m})$ em oito locais de presença abundante de pínus com idade inferior a 5 anos, sendo 5 parcelas em solos bem drenados e 3 parcelas em condições de solos mais úmidos próximos às APP's, onde foram cortados os indivíduos e monitoradas suas touças em termos de rebrotas.

Primeiramente, fez-se roçadas nas parcelas demarcadas, depois foram cortadas as plantas de pinus, a $10 \mathrm{~cm}$ do solo com motosserra. Procurou-se avaliar a influência da fase da lua na data do corte. Sendo assim, foram feitos cortes em dias chuvosos e em todo o espectro das fases da lua (nova, minguante, crescente e cheia).

De cada árvore, foram retirados dois discos, que foram acondicionados em sacos hermeticamente fechados, sendo levados para o LAMEF da UFPR, para a caracterização do teor de umidade corrente, após secagem em estufa a $105^{\circ} \mathrm{C}$. Todas as plantas de pínus foram numeradas e feitas medidas nas distâncias verticais e horizontais, em função de uma estaca principal em um dos cantos da parcela. Também foi feito o coroamento dos pinus para facilitar sua regeneração, evitando concorrência com plantas daninhas.

A presença de rebrota nos tocos das plantas cortadas foi monitorada por dois anos, tanto nos locais bem drenados quanto nas áreas permanentemente úmidas próximas às APP's.

\section{Resultados}

\section{Potencial de dispersão/germinação das sementes de Pinus taeda}

Foram verificados picos e depressões na disseminação de sementes. Durante o período de maior queda de sementes, destacam-se dois picos marcantes: o primeiro em agosto de 2005 e o segundo em julho de 2006.

De outubro a abril, nos dois anos de estudos, foi praticamente desprezível a quantidade de sementes disseminadas, não sendo capturada nenhuma semente nas caixas receptoras em nenhuma direção cardinal. Desta forma, procurou-se quantificar a queda das sementes e o percentual de germinação no período de maior concentração de disseminação das mesmas, procurando-se avaliá-las pelo ano, direção e distância (Tabela 2).

Nos dois anos, verificou-se maior captura de sementes de Pinus taeda, bem como maior percentual de germinação nas caixas receptoras localizadas a menores distâncias do talhão comercial de pinus, com 30 anos de idade. Salienta-se que a maior captura de sementes, nos dois anos de estudos, se deu na direção Sul.

Tabela 2. Total de sementes capturadas (SEM) e germinadas (GER), por ano, direção e distância do talhão comercial de Pinus taeda, em fazendas da Battistella Florestal S.A.

Table 2. Total number of seeds collected (SEM) and germinated (GER), per year, direction and distance from the commercial plot of Pinus taeda, on farms of Battistella Florestal S.A.

\begin{tabular}{|c|c|c|c|c|c|c|c|c|c|c|}
\hline \multirow[b]{3}{*}{ Distância } & \multicolumn{10}{|c|}{2005} \\
\hline & \multicolumn{2}{|c|}{$\mathbf{E}$} & \multicolumn{2}{|c|}{$\mathbf{N}$} & \multicolumn{2}{|c|}{$\mathbf{S}$} & \multicolumn{2}{|c|}{ W } & \multicolumn{2}{|c|}{ TOTAL } \\
\hline & Sem & Ger & Sem & Ger & Sem & Ger & Sem & Ger & Sem & Ger \\
\hline 25 & 24 & 17 & 5 & 1 & 331 & 149 & 66 & 25 & 426 & 192 \\
\hline 50 & 7 & 3 & 2 & 0 & 108 & 51 & 21 & 10 & 138 & 64 \\
\hline 75 & 1 & 0 & 1 & 1 & 59 & 24 & 3 & 2 & 64 & 27 \\
\hline 100 & 1 & 0 & 0 & 0 & 57 & 26 & 0 & 0 & 58 & 26 \\
\hline 125 & 0 & 0 & 0 & 0 & 40 & 17 & 0 & 0 & 40 & 17 \\
\hline 150 & 0 & 0 & 0 & 0 & 35 & 12 & 0 & 0 & 35 & 12 \\
\hline \multirow[t]{3}{*}{ TOTAL } & 33 & 20 & 8 & 2 & 630 & 279 & 90 & 37 & 761 & 338 \\
\hline & \multicolumn{10}{|c|}{2006} \\
\hline & \multicolumn{2}{|c|}{$\mathbf{E}$} & \multicolumn{2}{|c|}{$\mathbf{N}$} & \multicolumn{2}{|c|}{$\mathbf{S}$} & \multicolumn{2}{|c|}{ W } & \multicolumn{2}{|c|}{ TOTAL } \\
\hline Distância & Sem & Ger & Sem & Ger & Sem & Ger & Sem & Ger & Sem & Ger \\
\hline 25 & 20 & 6 & 22 & 8 & 323 & 142 & 48 & 16 & 413 & 172 \\
\hline 50 & 13 & 2 & 17 & 5 & 143 & 83 & 10 & 2 & 183 & 92 \\
\hline 75 & 6 & 2 & 1 & 0 & 59 & 22 & 5 & 1 & 71 & 25 \\
\hline 100 & 0 & 0 & 0 & 0 & 30 & 4 & 0 & 0 & 30 & 4 \\
\hline 125 & 0 & 0 & 0 & 0 & 21 & 5 & 0 & 0 & 21 & 5 \\
\hline 150 & 0 & 0 & 0 & 0 & 18 & 9 & 0 & 0 & 18 & 9 \\
\hline TOTAL & 39 & 10 & 40 & 13 & 594 & 265 & 63 & 19 & 736 & 307 \\
\hline
\end{tabular}

A análise de deviance (Tabela 3) para o total de sementes germinadas evidenciou efeito significativo para os efeitos principais de ano, direção e distância, além de interações para ano versus direção e ano versus distância (valor $\mathrm{p}<0,0001$ ). A deviance residual mostrou a adequação do modelo, embora este tenha evidenciado apenas efeitos significativos (valor $\mathrm{p}<0,005)$ para a interação direção versus distância. Verificou-se também que, além da maior concentração de sementes às distâncias de $25 \mathrm{~m}$ e $50 \mathrm{~m}$, estas também 
apresentaram maior poder germinativo, que pode estar relacionado ao maior vigor e peso das sementes. Quanto ao potencial de dispersão das sementes de $P$. taeda, a análise de deviance para o total de sementes capturadas evidenciou efeito significativo para os efeitos principais de ano, direção e distância, além do efeito da interação direção versus distância de ventos (valor $\mathrm{p}<0,0001$ ). Deve-se notar ainda, pela Tabela 3 , que a deviance do resíduo $(2.039,93)$ foi bastante superior ao número de graus de liberdade (896), mostrando a adequação do modelo utilizado, embora este tenha evidenciado apenas efeitos significativos com menor grau de confiança (valor $\mathrm{p}<0,005$ ) para as interações ano versus direção e ano versus distância. $\mathrm{O}$ efeito da interação direção versus distância é facilmente entendido pela elevada captura de sementes na direção Sul e distância de 25 m, em relação às demais direções e distâncias, conforme relatado anteriormente.

Tabela 3. Análise de deviance, considerando o fator de dispersão constante para o total de sementes de Pinus taeda capturadas.

Table 3. Deviance analysis, considering the dispersion factor constant for the total number of Pinus taeda seeds collected.

\begin{tabular}{ccccc}
\hline Causa da variação & Deviance & g.l. & $\chi^{2}$ & Valor p \\
\hline Ano & 5478,67 & 1 & 10.39 & 0,0013 \\
Direção & 3305,34 & 3 & 869,36 & $<0,0001$ \\
Distância & 1814,64 & 5 & 596,30 & $<0,0001$ \\
Ano x Direção & 1790,78 & 3 & 9,55 & 0,0228 \\
Ano x Distância & 1760,91 & 5 & 11,95 & 0,0355 \\
Direção x Distância & 1681,62 & 15 & 31,71 & 0,0070 \\
Ano x Direção x & 1660,14 & 15 & 8,59 & 0,8978 \\
Distância & & & & \\
Resíduo & 2039,93 & 816 & & \\
\hline
\end{tabular}

Os contrastes ortogonais (Tabela 4) corroboram com as informações de predominância do vento no local experimental. Evidenciou-se, por estes contrastes, uma diferença significativa (valor $\mathrm{p}<0,0001$ ) da orientação Sul em relação às demais orientações. Não foram observadas diferenças para as direções Leste e Oeste, entretanto, estas direções diferiram da orientação Norte, contrária ao sentido do vento, que proporcionou a menor concentração e germinação de sementes.

Os polinômios ortogonais evidenciaram, pelo valor do teste $\mathrm{F}$, a longevidade linear de dispersão e germinação das sementes (Tabela 5). Este fato revela que a maior dispersão e germinação ocorreram à distância de $25 \mathrm{~m}, \mathrm{e}$, à medida que se afasta da fonte fornecedora de sementes, estas também diminuíram.
Tabela 4. Teste dos contrastes ortogonais entre os efeitos principais de direção, considerando os efeitos de interação ano versus direção

Table 4. Test of orthogonal contrasts between the main effects of direction, considering the interaction effects year versus direction

\begin{tabular}{|c|c|c|c|c|c|}
\hline \multicolumn{6}{|c|}{ Ano de 2005} \\
\hline & & \multicolumn{2}{|c|}{ Total de sementes } & \multicolumn{2}{|c|}{ Germinação } \\
\hline Contraste & g.l. & $\chi^{2}$ & Valor $\mathbf{p}$ & $\chi^{2}$ & Valor $\mathbf{p}$ \\
\hline $\begin{array}{c}\text { Ne } \mathrm{S} \text { versus } \\
\mathrm{Le} \mathrm{W}\end{array}$ & 1 & 33,77 & $<0,0001$ & 35,79 & $<0,0001$ \\
\hline $\mathrm{N}$ versus $\mathrm{S}$ & 1 & 101,62 & $<0,0001$ & 103,4 & $<0,0001$ \\
\hline $\mathrm{L}$ versus $\mathrm{W}$ & 1 & 0,39 & 0,5350 & 0,97 & 0,3249 \\
\hline \multicolumn{6}{|c|}{ Ano de 2006} \\
\hline & & \multicolumn{2}{|c|}{ Total de sementes } & \multicolumn{2}{|c|}{ Germinação } \\
\hline Contraste & g.l. & $\chi^{2}$ & Valor $\mathbf{p}$ & $\chi^{2}$ & Valor $\mathbf{p}$ \\
\hline $\begin{array}{c}\mathrm{Ne} \mathrm{S} \text { versus } \\
\mathrm{Le} \mathrm{W}\end{array}$ & 1 & 18,37 & $<0,0001$ & 19,54 & $<0,0001$ \\
\hline $\mathrm{N}$ versus $\mathrm{S}$ & 1 & 37,64 & $<0,0001$ & 42,54 & $<0,0001$ \\
\hline $\mathrm{L}$ versus $\mathrm{W}$ & 1 & 0,05 & 0,8267 & 0,09 & 0,7686 \\
\hline
\end{tabular}

Em que: g.l. = grau de liberdade; $\chi^{2}=$ qui-quadrado.

Tabela 5. Teste dos polinômios ortogonais entre os efeitos principais de distância, considerando os efeitos de interação direção versus distância

Table 5. Test of the orthogonal polynomials between the main effects of distance, considering the of interaction effects of direction versus distance.

\begin{tabular}{cccccc}
\hline \multicolumn{5}{c}{ Total de sementes } & Germinação \\
\hline Polinômio & g.l. & Valor $\mathbf{F}$ & Valor $\mathbf{p}$ & Valor $\mathbf{F}$ & Valor $\mathbf{p}$ \\
\hline Linear & 1 & 30,25 & $<0,0001$ & 58,11 & $<0,0001$ \\
Quadrático & 2 & 24,25 & $<0,0001$ & 40,39 & $<0,0001$ \\
Cúbico & 3 & 17,64 & $<0,0001$ & 27,23 & $<0,0001$ \\
\hline \multicolumn{7}{c}{ Norte } \\
\hline Polinômio & g.l. & Valor $\mathbf{F}$ & Valor $\mathbf{p}$ & Valor $\mathbf{F}$ & Valor $\mathbf{p}$ \\
\hline Linear & 1 & 13,61 & 0,0003 & 33,91 & $<0,0001$ \\
Quadrático & 2 & 10,08 & $<0,0001$ & 25,08 & $<0,0001$ \\
Cúbico & 3 & 6,69 & 0,0002 & 16,72 & $<0,0001$ \\
\hline \multicolumn{7}{c}{ Sul } \\
\hline Polinômio & g.l. & Valor $\mathbf{F}$ & Valor $\mathbf{p}$ & Valor F & Valor $\mathbf{p}$ \\
\hline Linear & 1 & 69,48 & $<0,0001$ & 70,21 & $<0,0001$ \\
Quadrático & 2 & 52,56 & $<0,0001$ & 54,49 & $<0,0001$ \\
Cúbico & 3 & 36,2 & $<0,0001$ & 39,1 & $<0,0001$ \\
\hline \multicolumn{7}{c}{ Oeste } \\
\hline Polinômio & g.l. & Valor F & Valor $\mathbf{p}$ & Valor F & Valor $\mathbf{p}$ \\
\hline Linear & 1 & 72,38 & $<0,0001$ & 73,35 & $<0,0001$ \\
Quadrático & 1 & 62,18 & $<0,0001$ & 68,28 & $<0,0001$ \\
Cúbico & 1 & 44,85 & $<0,0001$ & 49,82 & $<0,0001$ \\
\hline
\end{tabular}

Em que: g.l. = grau de liberdade; $\chi^{2}=$ qui-quadrado. 


\section{Avaliação do potencial de contaminação pelo Pinus taeda em diversos ambientes}

Os ambientes externos aos plantios comerciais e passíveis de contaminação por $P$. taeda (Tabela 6) apresentaram-se significativamente diferentes em relação à presença de luminosidade na superfície do terreno. Estes ambientes também proporcionaram condições diferenciadas de germinação em suas superfícies.

Tabela 6. Comparações entre os índices de luminosidade (LUX) e percentual de germinação de sementes de Pinus taeda em diferentes ambientes no Planalto Norte do Estado de Santa Catarina passíveis de invasão biológica por esta espécie.

Table 6. Comparisons between luminosity indexes (LUX) and percentage of germination of Pinus taeda seeds in different sites in the Northern Plateau in Santa Catarina State, susceptible to biological invasion by this species.

\begin{tabular}{|c|c|c|c|c|}
\hline & \multicolumn{2}{|c|}{$\begin{array}{c}\text { Índices de } \\
\text { Luminosidade } \\
\text { (LUX) }\end{array}$} & \multicolumn{2}{|c|}{ Germinação (\%) } \\
\hline Capoeirão & 20.500 & $\mathrm{~cd}$ & 0 & $\mathrm{~b}$ \\
\hline APP_nascente d'água & 29.500 & bcd & 8 & $\mathrm{~b}$ \\
\hline Pedreira abandonada & 425.000 & $\mathrm{a}$ & 9 & $\mathrm{~b}$ \\
\hline Banhado & 78.000 & $\mathrm{abc}$ & 0 & $\mathrm{~b}$ \\
\hline Lajeado com gramíneas & 455.000 & $\mathrm{a}$ & 146 & a \\
\hline Taquaral & 44.525 & bcd & 0 & $b$ \\
\hline Floresta IMA & 5.600 & $\mathrm{~d}$ & 0 & $\mathrm{~b}$ \\
\hline Capoeirinha_vassoural & 143.250 & $\mathrm{ab}$ & 16 & $\mathrm{~b}$ \\
\hline APP_córrego & 29.375 & bcd & 0 & $\mathrm{~b}$ \\
\hline Pastagem natural & 27.500 & bcd & 0 & $\mathrm{~b}$ \\
\hline Pastagem queimada & 75.000 & $a b c$ & 9 & $\mathrm{~b}$ \\
\hline
\end{tabular}

Médias seguidas de mesma letra na coluna não diferem entre si pelo teste de Tukey $(\mathrm{p}>0,05)$.

\section{Avaliação do potencial de controle de Pinus taeda}

Os indivíduos de P. taeda cortados com idades inferiores a 5 anos, nos dois ambientes de estudos, ou seja, em local de solos bem drenados e em situações de solos mais úmidos, em áreas de preservação permanente (APP), não apresentaram em dois anos de observação quaisquer indícios de rebrota.

\section{Discussão}

A variação espaço-temporal gerada pelos fatores meteorológicos (principalmente ventos) no padrão de dispersão de sementes de Pinus taeda durante os dois anos de estudos em diferentes distâncias, variaram significativamente entre os pontos cardeais, tendo a maioria sido capturada nas caixas de coletas a menores distâncias $(25 \mathrm{~m}-50 \mathrm{~m})$ e no sentido da direção predominante do vento, ou seja, na direção Sul. Da mesma forma, o percentual de sobrevivência das sementes no estádio de germinação diminuiu significativamente com o aumento da distância dos pínus adultos, conforme esperado, uma vez que as sementes aladas mais leves e, portanto, com menor quantidade de material nutritivo, teriam menor poder germinativo nestas condições mais distantes.

Jemison \& Korstian (1944), trabalhando com povoamento de P. taeda, na Carolina do Norte (EUA), encontraram cerca de $70 \%$ das sementes disseminadas na faixa de $0 \mathrm{~m}$ a $40 \mathrm{~m}$ de distância da bordadura do talhão comercial e apenas 7\% na faixa de $90 \mathrm{~m}$ a $120 \mathrm{~m}$. Croker Junior \& Boyer (1975) relataram que o tempo e a duração da dispersão das sementes variam de acordo com as condições meteorológicas; e em seus trabalhos encontraram que a faixa de dispersão de sementes de pínus foi limitada, com $71 \%$ das sementes sadias caindo a uma distância de $20 \mathrm{~m}$ da base das árvores principais. Resultados semelhantes foram encontrados por Nathan et al. (2002), em estudo sobre a variação espaço-temporal no padrão de dispersão gerado pelo vento sobre sementes de $P$. halepensis, coletadas em armadilhas posicionadas a até $110 \mathrm{~m}$ de distância durante seis estações de dispersão sucessivas. Os autores verificaram que de 5.487 sementes, $97 \%$ estavam a $20 \mathrm{~m}$ da árvore adulta mais próxima.

Jankovski $(1985,1996)$ afirma que os picos de dispersão das sementes de pinus também podem ser causados pela umidade relativa do ar e pela precipitação. Segundo esse autor, pode ocorrer interação entre as variáveis meteorológicas, de forma que a ação de uma pode ocultar a ação da outra. $\mathrm{O}$ vento forte contribui para uma boa dispersão de sementes, mas a alta umidade proporciona o fechamento dos cones, não permitindo a saída das sementes de Pinus.

Segundo Jankovski $(1985,1996)$ e Ranieri et al. (2012), os picos e depressões na dispersão das sementes de pinus são causados por variáveis meteorológicas. Para estes autores, as variáveis meteorológicas que mostram maior influência são a temperatura, a umidade relativa do ar, a insolação e a velocidade do vento.

No entanto, Tomazello Filho et al. (2017) afirmaram que a distância da dispersão das sementes de $P$. taeda por ventos foi de $300 \mathrm{~m}$ (árvores de 16-25 anos), enquanto 
que Nathan et al. (2002) encontraram distâncias de dispersão de 200 m; Zanchetta et al. (2007) comentam que $90 \%$ das sementes de pinus se dispersaram entre $75 \mathrm{~m}$ e $90 \mathrm{~m}$, mas que podem atingir 5 a $8 \mathrm{~km}$ de distância. Bourscheid \& Reis (2010) indicam a dispersão de mais de 3 milhões de sementes ha ${ }^{-1}$ ano $^{-1}$ em plantações de pínus no Parque Florestal do Rio Vermelho, SC.

Bechara et al. (2013) determinaram dispersão de 204 sementes de pinus viáveis $\mathrm{m}^{-2}$ ano $^{-1}$, com uma taxa de germinação de $90 \%$. Ziller \& Galvão (2002) relataram que além da dispersão de significativa quantidade de sementes das árvores de Pinus spp., a longa distância deve ser considerada, bem como, a sua alta porcentagem de germinação, em muitos casos acima de $90 \%$. No entanto, em nossa pesquisa, o percentual de germinação médio foi de apenas $4 \%$ do total de sementes capturadas nas diversas distâncias dos talhões comerciais de $P$. taeda.

Ledgard \& Langer (1999) propõem para as empresas reflorestadoras as seguintes medidas de controle no manejo florestal para a minimização da invasão biológica por Pinus spp., nas vizinhanças de suas propriedades: os talhões devem ser alocados de modo que os seus eixos mais longos estejam direcionados para o sentido do vento predominante, para que a disseminação de sementes seja maior dentro do próprio talhão; a implantação de uma barreira de proteção com espécie não invasora de rápido crescimento; o corte de arvoretas oriundas da regeneração natural antes do início da conificação (geralmente entre cinco a oito anos de idade, dependendo do local); e, quando possível, plantios distantes de áreas protegidas.

Com relação aos estudos das áreas mais propensas à invasão por $P$. taeda, embora os ambientes com maior luminosidade, exceto o banhado (Tabela 6), tenham proporcionado os maiores índices de germinação, esses apenas diferiram do ambiente lajeado com gramíneas, o qual apresentou o maior número de sementes germinadas por área. Entretanto, deve-se ressaltar que mesmo neste ambiente, a germinação foi muito baixa (Tabela 6). A condição que favoreceu este local, em relação aos demais com mesmo nível de luminosidade, foi provavelmente a umidade uniforme do solo observada durante todo o ano.

$\mathrm{O}$ excesso de umidade, de forma permanente no ambiente banhado, embora com alta luminosidade, proporcionou o encharcamento das sementes de $P$. taeda, espécie que não tolera excessos de água e, consequentemente, levando-as à podridão (Shimizu
\& Sebbenn, 2008). No ambiente pedreira, apesar da alta luminosidade, houve inibição da germinação das sementes, muito provavelmente provocada pela desidratação das mesmas, resultando em baixas taxas de germinação $(1,13 \%)$.

Os ambientes APP, nascente d'água, APP, córrego e taquaral, apesar da boa e adequada uniformidade da umidade do solo, no decorrer dos dois anos de estudos, apresentaram baixa germinação e os ambientes Capoeirão e Floresta IMA, apresentaram germinação nula. Possivelmente, isso ocorreu devido ao baixo índice de luminosidade, condição que limita o crescimento de P. taeda (Pacheco et al., 2015).

$\mathrm{O}$ ambiente pastagem natural diferiu estatisticamente em termos de presença de luminosidade e, por conseguinte, do percentual de germinação do ambiente pastagem queimada induzida. No entanto, este último não correspondeu às expectativas em termos de quantidade de sementes germinadas, devido ao maior nível de perturbação da área experimental quando comparado com as condições naturais. Ziller (2000) observou em locais com queimadas anuais uma potencialização da invasão por $P$. elliottii Engelm. e $P$. taeda, em estepe gramíneo-lenhosa no Estado do Paraná, muito provavelmente pela maior presença de luminosidade nestes ambientes. Richardson \& Cowling (1992) afirmaram que o maior nível de degradação de um dado local resulta numa maior susceptibilidade à invasão por Pinus spp., por ser um gênero heliófito.

Os indivíduos cortados com idades inferiores a cinco anos não apresentaram quaisquer indícios de rebrotas. Tampouco, a época de corte, com relação às diferentes fases de lua e diferentes teores de umidade dos indivíduos analisados mostrou qualquer indício de rebrota no período estudado. Isto, provavelmente, esteja relacionado à altura do corte $(10 \mathrm{~cm}$ do solo), não deixando nenhuma gema que poderia ser capaz de prosperar dando vida a um novo indivíduo. Aguiar et al. (2013) afirmam haver muita dificuldade para o enraizamento de estacas de pinus, devido à incapacidade de rebrota das cepas após o corte raso, além de não responderem às outras técnicas para a indução de brotações basais, como o anelamento.

\section{Conclusões}

O potencial de dispersão e germinação de sementes de Pinus taeda nas condições edafoclimáticas do Planalto 
Norte do Estado de Santa Catarina indicou maior captura e viabilidade das sementes a curtas distâncias dos talhões-fontes, não ultrapassando em sua grande maioria $50 \mathrm{~m}$ de distância.

Constatou-se que os ambientes degradados, que apresentam maior luminosidade e com teores de umidade no solo mais uniformes durante todo o ano, apresentaram maior potencial de invasão.

O corte raso de plantas de $P$. taeda a $10 \mathrm{~cm}$ do solo é o suficiente para o seu controle, não ocorrendo rebrota.

\section{Agradecimentos}

Os autores agradecem à Battistella Florestal S.A. por não ter medidos esforços para o êxito desta pesquisa, além de fornecer todo o apoio logístico e financeiro para que este trabalho fosse desenvolvido da melhor maneira possível.

\section{Referências}

Aguiar, A. V. de et al. Cultivo de pínus: propagação vegetativa. REMADE: Revista da Madeira, n. 134, 2013. Disponível em: $<$ http://www.remade.com.br/br/revistadamadeira_materia.php?nu $\mathrm{m}=1657 \&$ subject $=$ Pinus\&title $=$ Cultivo $\% 20 \mathrm{de} \% 20 \mathrm{P} \%$ EDnus: $\% 20$ \%20Propaga\%E7\%E3o\%20vegetativa>. Acesso em: 09 abr. 2018.

Bechara, F. C. et al. Reproductive biology and early establishment of Pinus elliottii var. elliottii in Brazilian sandy coastal plain vegetation: implications for biological invasion. Scientia Agricola, v. 2, n. 70, p. 88-92, 2013.

Bourscheid, K. \& Reis, A. Dinâmica da invasão de Pinus elliottii Engelm. em restinga sob processo de restauração ambiental no Parque Florestal do Rio Vermelho, Florianópolis, SC. Biotemas, v. 23, n. 2, p. 23-30, 2010.

Croker Junior, T. C. \& Boyer, W. D. Regenerating Longleaf pine naturally. New Orleans: USDA Forest Service, Southern Forest Experiment Station, 1975. 21 p. (Research Paper SO-105).

Falleiros, R. et al. Invasão e manejo de Pinus taeda em campos de altitude do Parque Estadual do Pico Paraná, Paraná, Brasil. Floresta, v. 41, n. 1, p. 123-134, 2011.

Foelkel, E. \& Foelkel, C. O conceito de espécies invasivas ou invasoras em relação aos Pinus. PinusLetter, n. 4, 2008. Disponível em: $<$ http://www.celso-foelkel.com.br/Pinus_04.html $>$. Acesso em: 26 jun. 2018.

Global Invasive Species Programme. Global strategy on invasive alien species. Cambridge: IUCN Gland, 2001. Disponível em: $<$ http://www.issg.org/pdf/publications/GISP/Resources/McNeeleyetal-EN.pdf $>$. Acesso em: 23 jan. 2018.

Indústria Brasileira de Árvores. Relatório 2017. Brasília, DF, 2017. Disponível em <http://iba.org/images/shared/Biblioteca/ IBA_RelatorioAnual2017.pdf $>$. Acesso em: 10 abr. 2018.
Instituto Hórus. Espécies exóticas invasoras: fichas técnicas: pinus. São João de Meriti, 2016. Disponível em: $<$ http://www.institutohorus. org.br/index.php?modulo=inf_ficha_pinus_sp $>$. Acesso em: 26 jun. 2018.

Jankovski, T. Avaliação da produção e disseminação de sementes em um povoamento de P. taeda L. 1985. 74 f. Dissertação (Mestrado em Ciências Florestais) - Universidade Federal do Paraná, Curitiba. Jankovski, T. Estudo de alguns aspectos da regeneração natural induzida em povoamentos de Pinus taeda L. e Pinus elliottii Engelm. Floresta, v. 26, n. 1/2, p. 95-96, 1996.

Jemison, G. M. \& Korstian, C. F. Loblolly pine seed production and dispersal. Journal of Forestry, n. 42, p. 734-741, 1944.

Ledgard, N. J. \& Langer, E. R. Wilding prevention- guidelines for minimizing the risk of unwanted wilding spread from new plantings of introduced conifers. Christchurch: New Zealand Forest Research Institute, 1999.

Lockwood, J. L. et al. The more you introduce the more you get: the role of colonization pressure and propagule pressure in invasion ecology. Diversity and Distributions, n. 15, p. 904-910, 2009. DOI: 10.1111/j.1472-4642.2009.00594.x.

Miashike, R. L. Invasão por Pinus spp. em fisionomias campestres do Cerrado, no estado de São Paulo. 2015. 101 f. Dissertação (Mestrado em Ciências) - Universidade de São Paulo, São Paulo.

Nathan, R. et al. Mechanisms of long-distance dispersal of seeds by wind. Nature, v. 418, n. 6896, p. 409-413, 2002. DOI: 10.1038/ nature00844.

Pacheco, J. M. et al. Efeito da densidade inicial no crescimento de Pinus taeda L. na região Centro Sul do Paraná. Scientia Forestalis, v. 43, n. 106, p. 353-365, 2015.

Pivello, V. R. Invasões biológicas no cerrado brasileiro: efeitos da introdução de espécies exóticas sobre a biodiversidade. Ecologia. info, n. 33, 2015. Disponível em: <http://www.ecologia.info/cerrado. htm>. Acesso em: 26 jun. 2018.

Ramos, M. Disseminação e presença de Pinus elliottii Engelm. nas áreas ripárias da Floresta Nacional de Capão Bonito - SP, Brasil. 2015. Dissertação (Mestrado em Ciências) - Universidade de São Paulo, 2015

Ranieri, B. D. et al. Fenologia reprodutiva, sazonalidade e germinação de Kielmeyera regalis Saddi (Clusiaceae), espécie endêmica dos campos rupestres da Cadeia do Espinhaço, Brasil. Acta Botanica Brasilica, v. 3, n. 26, p. 632-641, 2012. DOI: 10.1590/ S0102-33062012000300012.

Richardson, D. M. \& Cowling, R. M. Why is mountain fynbos invasible and wich species invade? In: Van Wilgen, B. W. et al. (Ed.). Fire in South African mountain fynbos. Berlin: Springer-Verlag, 1992. p. 161-181.

Richardson, D. M. Pinus a model group for unlocking the secrets of alien plant invasions? Preslia, v. 78, n. 4, p. 375-388, 2006.

Simberloff, D. et al. Spread and impact of introduced conifers in South America: Lessons from other southern hemisphere regions. Austral Ecology, v. 35, p. 489-504, 2010.

Simberloff, D. The role of propagule pressure in biological invasions. Annual Review of Ecology Evolution, and Systematics, v. 40, p. 81-102, 2009. 
Shimizu, J. Y. \& Sebbenn, A. M. Espécies de pínus na silvicultura brasileira. In: Shimizu, J. Y. (Ed.). Pinus na silvicultura brasileira. Colombo: Embrapa Florestas, 2008. p. 49-74.

Tomazello Filho, M. et al. Avaliação da dispersão de sementes de Pinus taeda L. pela análise dos anéis de crescimento de árvores de regeneração natural. Floresta e Ambiente, n. 24: e00040913, 2017. DOI: $10.1590 / 2179-8087.040913$.

Vasques, A. G. et al. Uma síntese da contribuição do gênero Pinus para o desenvolvimento sustentável no sul do brasil. Floresta, v. 37 , n. 3, p. 445-450, 2007.

Zanchetta, D. S. et al. Análise biofísica dos processos envolvidos na invasão biológica de sementes de Pinus elliottii na Estação Ecológica de Itirapina - SP e alternativas de manejo. Climatologia e Estudos da Paisagem, n. 2, v. 1. p. 72-90, 2007.
Zenni, R. D. \& Simberloff, D. Number of source populations as a potential driver of pine invasions in Brazil. Biological Invasions, v. 15 , n. 7, p. 1623-1639, 2013.

Zenni, R. D. \& Ziller, S. R. An overview of invasive plants in Brazil. Revista Brasileira de Botânica, v. 34, n. 3, p. 431-446, 2011.

Ziller, S. R. A estepe gramíneo-lenhosa no segundo planalto do Paraná: diagnóstico ambiental com enfoque à contaminação ambiental. 2000. Tese (Doutorado em Engenharia Florestal) Universidade Federal do Paraná, Curitiba.

Ziller, S. R. \& Galvão, F. A degradação da estepe gramíneo-lenhosa no Paraná por contaminação biológica de Pinus elliotti Engelm. e P. taeda. L. Floresta, v. 32, n. 1, p. 41-47, 2002.

Ziller, S. R. Os processos de degradação ambiental originados por plantas invasoras. Ciência Hoje, v. 30, n. 178, p. 77-79, 2001. 